Alders, I., Henselmans, I., Smits, C., Visscher, T., Heijmans, M., Rademakers, J., Brand, P.L.P., Dulmen, S. van. Patient coaching in specialist consultations. Which patients are interested in a coach and what communication barriers do they perceive? Patient Education and Counseling: 2019, 8, p. 1520-1527

$\begin{array}{ll}\text { Postprint version } & : \\ \text { Journal website } & : \frac{\text { https://www.sciencedirect.com/science/article/pii/S0738399118305652 }}{\text { ?via\%3Dihub }} \\ \text { Pubmed link } & : \frac{\text { https://www.ncbi.nlm.nih.gov/pubmed/30910403 }}{\text { DOI }} \\ \text { : } & 10.1016 / \text { j.pec.2019.03.011 }\end{array}$

This is a Nivel certified Post Print, more info at nivel.nl

\title{
Patient coaching in specialist consultations. Which patients are interested in a coach and what communication barriers do they perceive?
}

\author{
Irèn Alders ${ }^{\text {a, b }}$, Inge Henselmans ${ }^{\mathrm{g}}$, Carolien Smits ${ }^{\mathrm{b}}$, Tommy Visscher ${ }^{\mathrm{b}}$, \\ Monique Heijmans ${ }^{\text {e }}$, Jany Rademakers ${ }^{\text {e, }}$, Paul L.P. Brand ${ }^{\text {c, d }}$, Sandra van \\ Dulmen ${ }^{a, e, f}$
}

\begin{abstract}
Objective

To characterize patients interested in support by a patient coach to guide them in medical specialist consultations.

Methods

We compared 76 patients interested in a patient coach with 381 patients without such an interest, using a representative panel of patients with a chronic disease in the Netherlands. Independent variables were demographic factors, socio-economic status, perceived efficacy in patient-provider interaction, communication barriers, health literacy, (duration and type of) disease(s) and activation level.

Results

In univariate analyses, patients who are interested in a coach were significantly older, had lower health literacy skills and less self-efficacy and, overall, experienced more communication barriers (>4), than patients without such interest (1-2 barriers). Multivariate analyses indicated three communications barriers as determinants of patient interest in a coach: feeling tense, uncertainty about own understanding, and believing that a certain topic is not part of a healthcare providers' task.

Conclusion

Patients interested in a coach perceive specific barriers in communicating with their medical specialist. In addition, patients who are $>=65$ years, have lower health literacy and low self-efficacy may have interest in a coach.

Practice implications

Characterizing patients interested in a patient coach facilitates identification of those who could benefit from such a coach in clinical practice.
\end{abstract}


Alders, I., Henselmans, I., Smits, C., Visscher, T., Heijmans, M., Rademakers, J., Brand, P.L.P., Dulmen, S. van. Patient coaching in specialist consultations. Which patients are interested in a coach and what communication barriers do they perceive? Patient Education and Counseling: 2019, 8, p. 1520-1527

\section{Introduction}

Patients with chronic illnesses are increasingly expected to be involved in treatment decisions to selfmanage their disease. Effective communication, requiring patients' active participation in dialogue with their physician, leads to better health and psychosocial outcomes in patients [[1], [2], [3]]. However, patients still perceive barriers to effective communication during medical specialist consultations in secondary care [[4], [5], [6]]. Secondary care in the Netherlands is organized in a hospital, which is a more complex environment than the practice of a general practitioner, and patients can feel lost and overwhelmed by this context [6]. Furthermore, almost half of all patients with a chronic disease experience barriers in the communication with their medical specialist (49.5\%) [7].

Henselmans et al found that significantly more patients were interested in a patient coach to prepare, accompany and evaluate a consultation with a medical specialist than with their general practitioner or nurse [7]. A personal coach to support patients in specialist consultations may help to find solutions for communication problems like age-related barriers (e.g. information processing abilities [8], remembering information [9], question articulation, and interactional barriers such as a dialect or hearing impairment) [1]. Personal coaching may help patients to develop communication skills by modelling and provides experiential learning when applied in the context of a consultation [[10], [11], [12]].

Perceived communication barriers in the interaction between patient and medical specialist are related to the patient's communication state after diagnosis. After diagnosis, patients ideally move through three consecutive communication states: 1) overwhelmed, passive; 2) pro-active, selfmotivated; and 3) proficient, empowered. In the empowered state patients have learned what questions they want to ask and how to ask them [4]. However, not all patients reach the third state; this evolution depends on various factors, like personal attributes and previous experiences. These factors and interpatient variability suggest the need for personalized communication support to reach a more empowered state to effectuate optimal patient participation in consultations $[3,4,12]$.

Our recent systematic review showed that personal coaching has a positive effect on patient-medical specialist communication [13]. In this review, thirteen patient coach interventions were investigated on communication outcomes in seventeen studies, ten of which were of high methodological quality. All studies showed significant improvement in communication outcomes during consultation (immediate), after the consultation (intermediate), and after several weeks or months (long term) [13]. The included patients benefited most from a patient coach in preparing and rehearsing questions, reflecting on and evaluating behavior and actions, and supporting in making audiorecordings of consultations [13]. The improvement in communication did not appear to be diseaserelated, nor was it moderated by patients' demographic, socio-economic or health literacy status [13]. Potential referrers need to be able to recognize a patient who might be interested in a patient coach in medical specialist consultations. The current study aims to provide insight into the characteristics of patients with a chronic disease who have an interest in a patient coach, when visiting a medical specialist, to facilitate this recognition.

\section{Methods}

\subsection{Design}

This study is a secondary analysis of data collected in a study conducted by Henselmans et al. [7].

\subsection{Sample}

Data derived from the National Panel of the Chronically ill and Disabled (NPCD), a representative sample of the non-institutionalized chronically ill population in the Netherlands which is regularly assessed in a longitudinal study on the consequences of living with a chronic illness [14]. Patients were 
Alders, I., Henselmans, I., Smits, C., Visscher, T., Heijmans, M., Rademakers, J., Brand, P.L.P., Dulmen, S. van. Patient coaching in specialist consultations. Which patients are interested in a coach and what communication barriers do they perceive? Patient Education and Counseling: 2019, 8, p. 1520-1527

selected from a random sample of general practitioners in the Netherlands. A research assistant together with a general practitioner looked at every third patient (alphabetical) in the total patient population. When a patient fulfilled the inclusion criteria (at least one medical diagnosis of a chronic somatic disease, age $>=16$, not terminally ill, mentally able to participate, and sufficiently mastering Dutch to understand the questions in the questionnaire) the patients got an invitation to participate. All patients selected from general practitioners had one or more medical diagnoses. We registered up to four diagnoses. All four diagnoses were included in our analysis (hence, patients could have more than one disease). Patients are invited to fill out questionnaires twice a year. People who had difficulties with reading or writing were interviewed by phone. The NPCD is registered with the Dutch Data Protection Authority; all data were collected and handled in accordance with privacy protection guidelines of the Authority.

In the original study, 1314 patients with a medical diagnosis of one or more chronic diseases completed questions about their interest in various kinds of support when visiting a nurse, a general practitioner or a medical specialist. Patients were asked: 'Which type of care provider is mainly responsible for your current treatment or monitoring?'. They answered subsequent questions, bearing this provider in mind [7]. We selected all patients that indicated a medical specialist as their main provider and analyzed this subsample $(n=457)$, All patients with an interest in a patient coach $(n=76)$ had seen their medical specialist in the past year.

\subsection{Ethical considerations}

Because this was a retrospective analysis of data previously collected and analyzed anonymously, this study was exempt from medical ethics review under Dutch law.

\subsection{Variables/measures}

Our dependent variable was patient's interest in support by a personal coach to prepare, accompany and evaluate a consultation with a medical specialist.

If patients were interested in support, they could indicate which kind of support would help them to participate in specialist consultations, e.g. to ask questions and to express their worries and concerns. Endorsement of interventions to support patients in their communication with their medical specialist was assessed with a list providing seven examples of support modalities [15] from which they could choose one or more suggestion(s) by indicating 'yes' or 'no'. Suggestions were introduced with the phrase: 'It would have been helpful for me if...'. Half of the proposed interventions were non-personal and informational, i.e. question prompt lists for personal use, information on how to prepare a consultation or modelling video's, and the other half were coaching (personal) interventions, i.e. a preparatory conversation with a nurse, a workshop with personal advice and exercises, and a patient coach. A patient coach was described as: '...if I would have a companion ('begeleider' in Dutch) who would accompany me to consultations with the healthcare provider and who prepares these consultations with me, accompanies me and evaluates them'. Interest in support by a patient coach was defined as an affirmative answer to this suggestion.

Patients provided data on demographic and socioeconomic characteristics (age, sex, highest educational level, living situation, ethnicity). Age was dichotomized as $<$ or $>=65$ years. As communication with elderly patients is more challenging [[16], [17], [18]], we wanted to make a distinction between patients younger and older than 65 years of age. Living situation was dichotomized into living alone or with others. Educational level was categorized in high (college or university), medium (high school) or low (vocational training). Ethnicity was indicated as country of birth by which patients were categorized as Dutch natives, Western and non-Western migrants, in accordance with Dutch standard categorization.

Clinical characteristics were recorded upon inclusion in the panel. The type and number of medical diagnoses of chronic somatic diseases were registered by the general practitioner at inclusion. Up to four somatic chronic diseases were registered. The earliest disease was categorized as cardio-vascular 
Alders, I., Henselmans, I., Smits, C., Visscher, T., Heijmans, M., Rademakers, J., Brand, P.L.P., Dulmen, S. van. Patient coaching in specialist consultations. Which patients are interested in a coach and what communication barriers do they perceive? Patient Education and Counseling: 2019, 8, p. 1520-1527

disease, respiratory disease, musculoskeletal disease, cancer, diabetes mellitus, neurological disease, chronic intestinal disease, and other chronic disease. The existence of comorbidity was recorded if one or more additional medically diagnosed chronic diseases besides the earliest disease were registered by the general practitioner at inclusion. Illness duration was calculated from the date of diagnosis of the earliest disease to time of filling out the questionnaire.

Patients answered questions using questionnaires to assess information preference, the level of health literacy and activation, for personal characteristics. Patients' information preference was assessed by responding to the question: 'How much information do you usually want about your disease or treatment?' on an 11-point Likert scale (0-10, 0 = least possible, $10=$ as much as possible) $[19,20]$. Scores were categorized 'limited' (0-6), 'extended' (7-9) and 'complete' (10) [19,20].

Patient's health literacy was assessed using the 3-item Set of Brief Screening Questions, Dutch version (SBSQ-D) [21,22]. This questionnaire consists of three statements assessing the ability to read and understand medical information (e.g. 'How confident do you feel in filling out medical forms by yourself?'). Responses are scored on a 5 point Likert scale (never, rarely, sometimes, often, always) and summed. A total score of $<=9$ indicates inadequate health literacy and a score $>9$ indicates adequate health literacy [22].

The level of patient activation (knowledge, skills and confidence in managing healthcare) was measured using the validated Dutch version of the Patient Activation Measure (PAM-13) [23]. This instrument scores four levels of activation, with higher levels indicating stronger activation [24]. The patients' experience of the interaction with their medical specialist was measured using questionnaires on perceived efficacy and communication barriers. Perceived efficacy in interaction was assessed with the validated 5-item Dutch version of the Perceived Efficacy In Patient-Physician Interactions-scale (PEPPI-5) [25,26]. Questions were introduced with: 'How confident are you that during the visit to your healthcare provider, you ......'. Patients could answer questions on their confidence in self-efficacy on a 5-point Likert scale ( 1 = not at all confident, $5=$ completely confident). To support interpretation, scores were dichotomized into 'not confident (1-3)' and 'confident (>3)'. Perceived barriers were assessed using a list of 17 barriers, adopted from the literature [27,28], a previous study [15] or added as hypotheses in the study by Henselmans et al. [7]. Patients could choose one or more suggested barriers and add barriers themselves by completing an open-ended question. Barriers were introduced with: 'I sometimes find it difficult to say something in a conversation with my healthcare provider, because ...'. Answers to the open-ended questions were transferred to the listed barriers when appropriate. In our analysis answers were excluded if they did not really represent barriers, but were in fact remarks on the relationship with the medical specialist (e.g. 'Have confidence in the medical specialist', 'Am very satisfied with my medical specialist').

\subsection{Analysis}

Differences in characteristics between patients with and without interest in a patient coach when consulting a medical specialist, perceived efficacy and barriers were tested using univariate analysis (Pearson chi2 and Fisher's exact test ( 2 sided)). To determine which barriers are most frequently reported by patients with and without an interest in a patient coach, descriptive statistics were used (crosstabs).

To examine the predictors of an interest in a patient coach in specialist consultations, logistic regression was used including the categorical predictor variable(s) that were significantly associated with an interest in a coach in univariate analysis. To identify possible relations between these predictor variable(s) in the model, we conducted a stepwise logistic regression (method: enter) in three steps. In the first model we entered the independent personal and clinical variables. In the second model we added perceived efficacy, and in the third model we added perceived barriers. All variables in the model were dichotomized.

To evaluate the predictive value of each independent variable in the final logistic regression model and of the model as a whole, we calculated the area under the curve (AUC) of the receiver operating 
Alders, I., Henselmans, I., Smits, C., Visscher, T., Heijmans, M., Rademakers, J., Brand, P.L.P., Dulmen, S. van. Patient coaching in specialist consultations. Which patients are interested in a coach and what communication barriers do they perceive? Patient Education and Counseling: 2019, 8, p. 1520-1527

characteristic (ROC) curve of these variables and of the entire model ( $A \cup C>9=$ excellent test, good specificity and sensitivity, $>8=$ good, $>7=$ fair, $>6=$ poor,$<6=$ no value as test instrument) [29]. Analyses were carried out using SPSS version 25 .

\section{Results}

\subsection{Characteristics of patients with and without interest in a coach}

In the original study, 1669 patients received the questionnaire, 1373 of whom returned it (82.3\%), and 1314 were eligible. 457 Patients considered the medical specialist as their main healthcare provider (34.8\%) and were included as subjects in the current analysis. Seventy-six (16.6\%) of them were interested in support by a patient coach when visiting their medical specialist. The characteristics and the results of the univariate analyses of patients with or without interest in a patient coach are presented in Table 1.

\section{[table 1]}

In the univariate analysis age $>=65$ years, having a neurological disease, and lower health literacy skills were associated with interest in support by a patient coach. Analysis of the type of neurological disease showed that most patients suffered from migraine. The patients had an average illness duration of 10 years. There were no significant differences between groups in illness duration. 3.2. Perceived efficacy and barriers

Patients interested in a patient coach in specialist consultations reported lower perceived efficacy than patients not interested in a coach (Table 2). Patients with interest in a patient coach reported a mean of four communication barriers (mean 4.3, SD 4.1), whereas patients without such an interest reported between one and two barriers (mean 1.7, SD 2.8). The most commonly reported barriers among patients with interest in a patient coach, in order of frequency, were: 'uncertainty about own understanding', 'belief the subject is not part of this providers task', 'looking up to the provider', 'not finding the right moment to bring something up', 'feeling tense' and 'not knowing what is expected of me'. Barriers most frequently reported by patients without interest in a patient coach, in order of frequency, were 'remembering subject only afterwards', 'perception there is too little time', 'not wanting to be bothersome', 'belief subject is not important enough', and 'feeling tense'.

\section{[table 2]}

\subsection{Multivariate analysis}

To determine independent predicting characteristics of patients interested in a patient coach or not, a stepwise multiple logistic regression analysis was conducted on the statistically significant variables resulting from the univariate analyses. The results of this regression analysis are presented in Table 3.

\section{[Table 3]}

Stepwise multiple logistic regression shows that patients are more likely to be interested in a patient coach in specialist consultations when they feel tense (aOR: $2.76,95 \% \mathrm{Cl}: 1.16-6.58$ ), are uncertain about their own understanding (aOR: $3.59,95 \% \mathrm{Cl}: 1.42-9.13$ ), and believe that a certain topic does not belong with this healthcare provider (aOR: $8.73,95 \% \mathrm{Cl}: 2.76-27.65)$. In addition, when patients suffer from a neurological disease they are less likely to be interested in a patient coach (aOR: 0.32 95Cl: 0.14-0.70).

In ROC analyses, the predictive value of each independent variable in the final logistic regression model (model 3, Table 3) was modest, with AUC's ranging from .568 to .621. 
Alders, I., Henselmans, I., Smits, C., Visscher, T., Heijmans, M., Rademakers, J., Brand, P.L.P., Dulmen, S. van. Patient coaching in specialist consultations. Which patients are interested in a coach and what communication barriers do they perceive? Patient Education and Counseling: 2019, 8, p. 1520-1527

\section{Discussion and conclusion}

\subsection{Discussion}

The main predictor of interest in a patient coach for patients with a chronic disease when consulting a medical specialist, is experiencing specific communication barriers (i.e. feeling tense, being uncertain about own understanding and believing the subject is not part of this healthcare provider's task). These barriers remain predictors after adjustment for other communication barriers and characteristics like being 65 years or older, low level of health literacy, being diagnosed with a neurological disease and low perceived efficacy in patient provider interaction. Following the framework of Feldman-Stewart these barriers can be classified as emotional barriers (feeling tense) and hindering beliefs (uncertainty about own understanding, subject is not part of providers' task) $[15,30]$. If a patient expresses these barriers, this should prompt potential referrers to explore the patient's need for additional support from a patient coach when visiting the medical specialist. When we focus on patient characteristics, the need for communication support depends on selfmanagement and communication skills [27,[31], [32], [33]]. The level of these skills is affected by age [34], patient activation level [35], educational level and socio economic status (SES) [36], sex [37], illness burden [38] and health literacy [[39], [40], [41]]. In our systematic review we did not find a relation between communication outcomes and these factors though [13], which is confirmed in the current study.

The current study shows that older age (>= 65 years), a lower level of health literacy and lower perceived efficacy in patient provider interaction, are in a univariate analysis related to the interest in a patient coach in patients with a chronic disease, but these do not remain predicting factors in the subsequent multivariate logistic regression. Other studies also found no significant differences in interest in support between younger and older patients with cancer [5].

Patients suffering from a neurological disease seem to be less likely to be interested in a patient coach. This is a remarkable outcome, which we cannot explain based on our current data. The reasons for this might by subject for further research, though the number of patients was relatively small in our survey ( $n=57$ ) and these results might also be chance finding.

Lower health literacy skills are known to be a risk factor to experience barriers [7]. Health literacy can be determined in several ways related to different definitions. In our study the SBSQ-D questionnaire on functional health literacy was used, which distinguishes between lower and higher educated groups [22]. Other questionnaires that use a broader definition of health literacy might show other results. Perceived efficacy in patient provider interaction is also known to be related to perceived barriers, though less strongly than health literacy [7]. The correct understanding of medical terms (i.e. health literacy) is related to higher confidence in understanding (the opposite is indicating a barrier). According to Pieterse et al, [41] complex medical language does not affect measures of perceived efficacy, but when a patient expresses low confidence in understanding medical terms this might be an indication to explore the patient's interest in a coach.

A remarkable observation in this study is that the patients in this sample were 'experienced' in the healthcare system (mean illness duration 10 years, mean number of contacts with medical specialist per year: 1-2), but illness duration and number of contacts did not influence patient's interest in a coach when consulting their medical specialist. This is consistent with the results of Van Bruinessen et al. showing that patients show changing communication attitudes, skills and perceived barriers over time, and time since diagnosis or phase in the disease was not a predictor of the communication state [4]. These findings substantiate the recommendation to simply ask patients with a chronic disease, consulting a medical specialist, about perceived barriers repeatedly during their treatment trajectory. It still remains to be determined what a personal intervention to support patients with a chronic disease visiting a medical specialist, to overcome aforementioned barriers, should comprise. Personal attention is fundamental for patients to feel heard and respected [42]. A patient coach could support a 
Alders, I., Henselmans, I., Smits, C., Visscher, T., Heijmans, M., Rademakers, J., Brand, P.L.P., Dulmen, S. van. Patient coaching in specialist consultations. Which patients are interested in a coach and what communication barriers do they perceive? Patient Education and Counseling: 2019, 8, p. 1520-1527

patient in preparation of the consultation by, for example, a comprehensive assessment of the patient's perceived barriers, preferences, concerns, needs and communication state $[4,43,44]$. This might increase the perceived value of their own needs and preferences [45], lower tension and provide opportunity to practice communication skills [6]. However, most personal interventions are provided only once, and outside the consultation room $[6,10,11,46]$, which disregards prerequisites for learning skills and behavioral change $[47,48]$, and the perceived barriers in the actual consultation.

\subsection{Strengths and limitations}

A strength of this study is the use of a representative panel of the Dutch population of chronically ill patients, including adult persons with various chronic diseases. In this study, patients specifically answered the question about a personal coach to help them prepare, attend and evaluate consultations with a medical specialist.

We acknowledge the following limitations. This study is a secondary analysis of data collected to answer other research questions [7]. Other questions and suggestions might have been more suitable to answer our research questions. Although the outcomes of the possible determinants are significant, the predictive value is modest, which is to be expected in self-reported questionnaires not specifically designed to predict the interest in a coach in specialist consultations. The panel responded to questionnaires sent in 2011, and in the meantime interventions have been developed and implemented to support patients in participation. On the other hand, empirical information on personal coaching is still scarce [13].

Patients in our study did already know their medical specialist. The interest in support by a patient coach might differ for patients who are newly referred to a medical specialist they don't know. Future research should study a patient's interest in a patient coach when the patient is newly referred to a medical specialist.

Patient coaching was described as support by a personal coach to prepare, accompany and evaluate consultations. The description of the patient coach was rather concise and it could be that patients interpreted the meaning of the word 'coach' differently, for example a relative or a friend. An important issue in this matter is the availability of a family member or friend to accompany the patient. Not all patients have someone to accompany them [49]. In oncology consultations, triadic communication which involves carers can be helpful, but also challenging (e.g. demanding behaviors, dominating the conversation) [50]. Some patients prefer family members for example as interpreter, because they make them feel empowered if this person is also an advocate for the patient. Patients trust them. In consultations they are often the first interlocutor. On the other hand, if patients feel dominated by and dependent of this person, it is not supportive during the consultation. In these situations a professional companion/coach might be the second best choice, if trust and fidelity of the professional is guaranteed [[51], [52], [53], [54], [55]].

In this study the Set of Brief Screening Questions, Dutch version (SBSQ-D) questionnaire to discover the level of health literacy was used, while it may have been helpful to (also) characterize patients by a more broad definition of health literacy [56,57].

\subsection{Conclusion}

Patients with a chronic disease show interest in support by a patient coach to help prepare, accompany and evaluate consultations with a medical specialist, especially when they indicate they are feeling tense, are uncertain about their own understanding or feel that not all subjects are appropriate to discuss with a medical specialist. These barriers are strongly related to patients' perceived efficacy in communication and their level of health literacy. A patient expressing one of these barriers should prompt the healthcare provider to explore the patient's need for additional support from a patient coach when visiting the medical specialist. 
Alders, I., Henselmans, I., Smits, C., Visscher, T., Heijmans, M., Rademakers, J., Brand, P.L.P., Dulmen, S. van. Patient coaching in specialist consultations. Which patients are interested in a coach and what communication barriers do they perceive? Patient Education and Counseling: 2019, 8, p. 1520-1527

\subsection{Practice implications}

When potential referrers know what barriers patients with a chronic disease with and without interest in a patient coach perceive when consulting their medical specialist, they can discuss interest for a personal coach with this patient. Insight in the characteristics of patients who are interested in a patient coach and in the type of barriers they perceive are prerequisites to attune a personal supportive intervention.

Patient coaching needs to be better defined, theoretically underpinned and investigated. Future studies should investigate the influence of health literacy in a broader definition, also investigate the influence of suffering from a neurological disease, ethnicity and culture on the interest in a patient coach, as well as patients' actual need for a patient coach, when facing a consultation with a medical specialist.

\section{Conflict of interest}

The authors declare no conflict of interest.

\section{Funding resources}

The NPCD is financed by the Ministry of social affairs and employment and the Ministry of health, welfare and sports.

\section{Acknowledgements}

We would like to thank the participants of the NPCD, this study would not have been possible without their collaboration. Furthermore we would like to thank Rob van Erven for his help with the statistical analysis.

\section{References}

[1] J. Harrington, L.M. Noble, S.P. NewmanImproving patients' communication with doctors: a systematic review of intervention studies Patient Educ. Couns., 52 (1) (2004), pp. 7-16

[2] S.M. KurtzDoctor-patient communication: principles and practices Can. J. Neurol. Sci., 29 (Suppl. 2) (2002), pp. S23-S29

[3] E. Schmidt, A.C. Schopf, E. FarinWhat is competent communication behaviour of patients in physician consultations? - Chronically-ill patients answer in focus groups Psychol. Health Med., 22 (8) (2017), pp. 987-1000

[4] I.R. van Bruinessen, E.M. van Weel-Baumgarten, H. Gouw, J.M. Zijlstra, A. AlbadaD.S. van, Barriers and facilitators to effective communication experienced by patients with malignant lymphoma at all stages after diagnosis Psychooncology, 22 (12) (2013), pp. 2807-2814

[5] J. Noordman, J.A. Driesenaar, I. Henselmans, J. Verboom, M. Heijmans, S. van DulmenPatient participation during oncological encounters: barriers and need for supportive interventions experienced by elderly cancer patients Patient Educ. Couns., 100 (12) (2017), pp. 2262-2268

[6] N. Joseph-Williams, G. Elwyn, A. EdwardsKnowledge is not power for patients: a systematic review and thematic synthesis of patient-reported barriers and facilitators to shared decision making Patient Educ. Couns., 94 (3) (2014), pp. 291-309

[7] I. Henselmans, M. Heijmans, J. Rademakers, S. van DulmenParticipation of chronic patients in medical consultations: patients' perceived efficacy, barriers and interest in support Health Expect., 18 (6) (2015), pp. 2375-2388

[8] L.M. van Vliet, E. Lindenberger, J.C. van WeertCommunication with older, seriously ill patients Clin. Geriatr. Med., 31 (2) (2015), pp. 219-230

[9] E.R. Posma, J.C. van Weert, J. Jansen, J.M. BensingOlder cancer patients' information and support needs surrounding treatment: an evaluation through the eyes of patients, relatives and professionals BMC Nurs., 8 (2009), p. 1 
Alders, I., Henselmans, I., Smits, C., Visscher, T., Heijmans, M., Rademakers, J., Brand, P.L.P., Dulmen, S. van. Patient coaching in specialist consultations. Which patients are interested in a coach and what communication barriers do they perceive? Patient Education and Counseling: 2019, 8, p. 1520-1527

[10] A. Bandura, A.C. Hustonldentification as a process of incidental learning J. Abnorm. Soc. Psychol., 63 (1961), pp. 311-318

[11] V. van den Eertwegh, S. van Dulmen, J. van Dalen, A.J. Scherpbier, C.P. van der VleutenLearning in context: identifying gaps in research on the transfer of medical communication skills to the clinical workplace Patient Educ. Couns., 90 (2) (2013), pp. 184-192

[12] I. Aujoulat, W. d'Hoore, A. DeccachePatient empowerment in theory and practice: polysemy or cacophony? Patient Educ. Couns., 66 (1) (2007), pp. 13-20

[13] I. Alders, C. Smits, P. Brand, S. van DulmenDoes patient coaching make a difference in patientphysician communication during specialist consultations? A systematic review Patient Educ. Couns., 100 (5) (2017), pp. 882-896

[14] M. Rijken, M. van Kerkhof, J. Dekker, F.G. SchellevisComorbidity of chronic diseases

Qual. Life Res., 14 (1) (2005), pp. 45-55

[15] I. Henselmans, M. Jacobs, M.I. van Berge Henegouwen, H.C.J.M. de Haes, M.A.G. Sprangers, E.M.A. SmetsPostoperative information needs and communication barriers of esophageal cancer patients Patient Educ. Couns., 88 (1) (2012), pp. 138-146

[16] S.L. Williams, K.B. Haskard, M.R. DiMatteoThe therapeutic effects of the physician-older patient relationship: effective communication with vulnerable older patients Clin. Interv. Aging, 2 (3) (2007), pp. 453-467

[17] S.C. Brown, D.C. ParkTheoretical models of cognitive aging and implications for translational research in medicine Gerontologist, 43 (2003), pp. 57-67 Spec No 1

[18] S.A. Valentijn, M.P. van Boxtel, S.A. van Hooren, H. Bosma, H.J. Beckers, R.W. Ponds, J. JollesChange in sensory functioning predicts change in cognitive functioning: results from a 6-year follow-up in the Maastricht aging study J. Am. Geriatr. Soc., 53 (3) (2005), pp. 374-380

[19] B.R. Cassileth, R.V. Zupkis, K. Sutton-Smith, V. MarchInformation and participation preferences among cancer patients Ann. Intern. Med., 92 (6) (1980), pp. 832-836

[20] L.C. Zandbelt, E.M. Smets, F.J. Oort, M.H. Godfried, H.C. de HaesDeterminants of physicians' patient-centred behaviour in the medical specialist encounter Soc. Sci. Med., 63 (4) (2006), pp. 899910

[21] L.D. Chew, K.A. Bradley, E.J. BoykoBrief questions to identify patients with inadequate health literacy Fam. Med., 36 (8) (2004), pp. 588-594

[22] M.P. Fransen, T.M. Van Schaik, T.B. Twickler, M.L. Essink-BotApplicability of internationally available health literacy measures in the Netherlands J. Health Commun., 16 (Suppl 3) (2011), pp. 134149

[23] J. Rademakers, J. Nijman, L. van der Hoek, M. Heijmans, M. RijkenMeasuring patient activation in the Netherlands: translation and validation of the American short form Patient Activation Measure (PAM13) BMC Public Health, 12 (2012), p. 577

[24] R.L. Skolasky, A.F. Green, D. Scharfstein, C. Boult, L. Reider, S.T. WegenerPsychometric properties of the patient activation measure among multimorbid older adults Health Serv. Res., 46 (2) (2011), pp. 457-478

[25] R.C. Maly, J.C. Frank, G.N. Marshall, M.R. DiMatteo, D.B. ReubenPerceived efficacy in patientphysician interactions (PEPPI): validation of an instrument in older persons J. Am. Geriatr. Soc., 46 (7) (1998), pp. 889-894

[26] P.M. ten Klooster, J.C.M. Oostveen, L.C. Zandbelt, E. Taal, C.H.C. Drossaert, E.J. Harmsen, M.A.F.J. van de LaarFurther validation of the 5 -item perceived Efficacy in Patient-Physician Interactions (PEPPI5) scale in patients with osteoarthritis Patient Educ. Couns., 87 (1) (2012), pp. 125-130

[27] J. Kidd, T.M. Marteau, S. Robinson, O.C. Ukoumunne, C. TydemanPromoting patient participation in consultations: a randomised controlled trial to evaluate the effectiveness of three patient-focused interventions Patient Educ. Couns., 52 (1) (2004), pp. 107-112 
Alders, I., Henselmans, I., Smits, C., Visscher, T., Heijmans, M., Rademakers, J., Brand, P.L.P., Dulmen, S. van. Patient coaching in specialist consultations. Which patients are interested in a coach and what communication barriers do they perceive? Patient Education and Counseling: 2019, 8, p. 1520-1527

[28] R. Borgers, P.D. Mullen, R. Meertens, M. Rijken, G. Eussen, I. Plagge, A.P. Visser, G.H. BlijhamThe information-seeking behavior of cancer outpatients: a description of the situation Patient Educ. Couns., 22 (1) (1993), pp. 35-46

[29] J.A. Hanley, B.J. McNeilThe meaning and use of the area under a receiver operating characteristic (ROC) curve Radiology, 143 (1) (1982), pp. 29-36

[30] D. Feldman-Stewart, M.D. Brundage, C. Tishelman, S.C. TeamA conceptual framework for patientprofessional communication: an application to the cancer context Psychooncology, 14 (10) (2005), pp. 801-809 discussion 810-1

[31] M.G. Ory, S. Ahn, L. Jiang, M.L. Smith, P.L. Ritter, N. Whitelaw, K. LorigSuccesses of a national study of the chronic disease self-management program: meeting the triple aim of health care reform Med. Care, 51 (11) (2013), pp. 992-998

[32] R.L. Kravitz, D.J. Tancredi, T. Grennan, D. Kalauokalani, J. Street, C.K. Slee, T. Wun, J.W. Oliver, K. Lorig, P. FranksCancer health empowerment for living without pain (Ca-HELP): effects of a tailored education and coaching intervention on pain and impairment Pain, 152 (7) (2011), pp. 1572-1582 [33] J.H. Barlow, A.P. Turner, C.C. WrightA randomized controlled study of the Arthritis SelfManagement Programme in the UK Health Educ. Res., 15 (2000), pp. 665-680

[34] B. Geboers, A.F. de Winter, S.L. Spoorenberg, K. Wynia, S.A. ReijneveldThe association between health literacy and self-management abilities in adults aged 75 and older, and its moderators Qual. Life Res., 25 (11) (2016), pp. 2869-2877

[35] H.A. Crawford, B. Barton, M.J. Wilson, Y. Berman, V.J. McKelvey-Martin, P.J. Morrison, K.N. NorthUptake of health monitoring and disease self-management in Australian adults with neurofibromatosis type 1: strategies to improve care Clin. Genet., 89 (3) (2016), pp. 385-391

[36] J. Youm, V. Chan, J. Belkora, K.J. Boziclmpact of socioeconomic factors on informed decision making and treatment choice in patients with hip and knee OA J. Arthroplasty (2014)

[37] V. CaponePatient communication self-efficacy, self-reported illness symptoms, physician communication style and mental health and illness in hospital outpatients J. Health Psychol., 21 (7) (2016), pp. 1271-1282

[38] L.J. Finney Rutten, B.W. Hesse, J.L. St Sauver, P. Wilson, N. Chawla, D.B. Hartigan, R.P. Moser, S. Taplin, R. Glasgow, N.K. AroraHealth self-efficacy among populations with multiple chronic conditions: the value of patient-centered communication Adv. Ther., 33 (8) (2016), pp. 1440-1451

[39] L.M. Mackey, C. Doody, E.L. Werner, B. FullenSelf-management skills in chronic disease management: what role does health literacy have? Med. Decis. Making, 36 (6) (2016), pp. 741-759

[40] R.H. Wang, H.C. Hsu, Y.J. Lee, S.J. Shin, K.D. Lin, L.W. AnPatient empowerment interacts with health literacy to associate with subsequent self-management behaviors in patients with type 2 diabetes: a prospective study in Taiwan Patient Educ. Couns., 99 (10) (2016), pp. 1626-1631 [41] M. Heijmans, G. Waverijn, J. Rademakers, R. Vaart van der, M. RijkenFunctional, communicative and critical health literacy of chronic disease patients and their importance for self-management Patient Educ. Couns., 98 (1) (2015), pp. 41-48

[42] K. Thorarinsdottir, K. KristjanssonPatients' perspectives on person-centred participation in healthcare: a framework analysis Nurs. Ethics, 21 (2) (2014), pp. 129-147

[43] P.M. Kane, F.E.M. Murtagh, K. Ryan, N.G. Mahon, B. McAdam, R. McQuillan, C. Ellis-Smith, C. Tracey, C. Howley, C. Raleigh, G. O'Gara, I.J. Higginson, B.A. DavesonThe gap between policy and practice: a systematic review of patient-centred care interventions in chronic heart failure Heart Fail. Rev., 20 (6) (2015), pp. 673-687

[44] S. Thorne, T.G. Hislop, C. Kim-Sing, V. Oglov, J.L. Oliffe, K.I. StajduharChanging communication needs and preferences across the cancer care trajectory: insights from the patient perspective Support. Care Cancer, 22 (4) (2014), pp. 1009-1015

[45] G. Gartlehner, N. MatyasHow contextual issues can distort shared decision making Z. Evid. Fortbild. Qual., 118-119 (2016), pp. 17-23 
Alders, I., Henselmans, I., Smits, C., Visscher, T., Heijmans, M., Rademakers, J., Brand, P.L.P., Dulmen, S. van. Patient coaching in specialist consultations. Which patients are interested in a coach and what communication barriers do they perceive? Patient Education and Counseling: 2019, 8, p. 1520-1527

[46] P. Kinnersley, A. Edwards, K. Hood, R. Ryan, H. Prout, N. Cadbury, F. MacBeth, P. Butow, C. ButlerInterventions before consultations to help patients address their information needs by encouraging question asking: systematic review BMJ, 337 (2008), p. a485

[47] M.S. Knowles, E.F. Holton, R.A. SwansonThe Adult Learner: The Definitive Classic in Adult Education and Human Resource Development Taylor \& Francis (2014)

[48] S.C. Hayes, J.B. Luoma, F.W. Bond, A. Masuda, J. LillisAcceptance and commitment therapy: model, processes and outcomes Behav. Res. Ther., 44 (1) (2006), pp. 1-25

[49] L. Del Piccolo, C. Goss, A. Bottacini, V. Rigoni, M.A. Mazzi, G. Deledda, M. Ballarin, A. Molino, E. Fiorio, C. ZimmermannAsking questions during breast cancer consultations: does being alone or being accompanied make a difference? Eur. J. Oncol. Nurs., 18 (3) (2014), pp. 299-304

[50] P. Butow, R. Laidsaar-Powell, I. Juraskova, C. Charles, W. Lam, A. GafniCarers in medical consultations: how can they support patients and be supported? PsychoOncology, 22 (2013), pp. 142143

[51] R. Zendedel, B.C. Schouten, J.C.M. van Weert, B. van den Puttelnformal interpreting in general practice: the migrant patient's voice Ethn. Health, 23 (2) (2018), pp. 158-173

[52] J. Hilder, B. Gray, A. Dowell, L. Macdonald, R. Tester, M. Stubbe'lt depends on the consultation': revisiting use of family members as interpreters for general practice consultations - when and why? Aust. J. Prim. Health, 23 (3) (2017), pp. 257-262

[53] B.C. Schouten, S. SchinkelTurkish migrant GP patients' expression of emotional cues and concerns in encounters with and without informal interpreters Patient Educ. Couns., 97 (1) (2014), pp. 23-29

[54] B. Gray, J. Hilder, H. DonaldsonWhy do we not use trained interpreters for all patients with limited English proficiency? Is there a place for using family members? Aust. J. Prim. Health, 17 (3) (2011), pp. 240-249

[55] R. Zendedel, B.C. Schouten, J.C. van Weert, B. van den Puttelnformal interpreting in general practice: comparing the perspectives of general practitioners, migrant patients and family interpreters Patient Educ. Couns., 99 (6) (2016), pp. 981-987

[56] D. NutbeamHealth literacy as a public health goal: a challenge for contemporary health education and communication strategies into the 21st century Health Promot. Int., 15 (3) (2000), pp. 259-267 [57] I. van der Heide, M. Heijmans, A.J. Schuit, E. Uiters, J. RademakersFunctional, interactive and critical health literacy: varying relationships with control over care and number of GP visits Patient Educ. Couns., 98 (8) (2015), pp. 998-1004 
Alders, I., Henselmans, I., Smits, C., Visscher, T., Heijmans, M., Rademakers, J., Brand, P.L.P., Dulmen, S. van. Patient coaching in specialist consultations. Which patients are interested in a coach and what communication barriers do they perceive? Patient Education and Counseling: 2019, 8, p. 1520-1527

\section{Table and Figure}

Table 1. Demographic and clinical characteristics of patients with and without interest in a coach in specialist consultations $(n=457)$.

\begin{tabular}{|c|c|c|c|c|}
\hline & & $\begin{array}{l}\text { Interested in a } \\
\text { coach }\end{array}$ & $\begin{array}{l}\text { Not interested in a } \\
\text { coach }\end{array}$ & $\begin{array}{l}\mathrm{p}- \\
\text { value }\end{array}$ \\
\hline & n & $(n=76), \%$ & $(n=381), \%$ & \\
\hline M (SD) & $62.8(11.7)$ & $65.8(12.9)$ & $62.2(11.4)$ & \\
\hline$<65$ & 256 & 44.7 & 58.3 & $.032 \#$ \\
\hline$>=65$ & 201 & 55.3 & 41.7 & \\
\hline \multicolumn{5}{|l|}{ Sex } \\
\hline Male & 246 & 56.6 & 53.3 & $.617 \#$ \\
\hline female & 211 & 43.4 & 46.7 & \\
\hline Educational level, M (SD) & & $1.8(.69)$ & $2.0(.77)$ & \\
\hline Low (1) & 134 & 33.8 & 28.9 & $.065 \# \#$ \\
\hline Medium (2) & 194 & 50.0 & 41.6 & \\
\hline High (3) & 123 & 16.2 & 29.4 & \\
\hline Living situation, $\mathrm{M}(\mathrm{SD})$ & & $.8(.39)$ & $1(0.81)$ & \\
\hline Living alone (1) & 86 & 18.7 & 18.9 & $1.00 \#$ \\
\hline Living together (2) & 369 & 81.3 & 81.1 & \\
\hline \multicolumn{5}{|l|}{ Ethnicity } \\
\hline Dutch born & 423 & 97.4 & 91.6 & .208\#\# \\
\hline Western migrants & 31 & 2.6 & 7.6 & \\
\hline Non Western migrants & 3 & 0.0 & 0.8 & \\
\hline \multicolumn{5}{|l|}{ Chronic diseases } \\
\hline Cardiovasculair disease & 148 & 28.9 & 33.1 & $.506 \#$ \\
\hline Respiratory disease (asthma, COPD) & 104 & 21.1 & 23.1 & $.766 \#$ \\
\hline Muskuloskeletal disease & 114 & 28.9 & 24.1 & $.386 \#$ \\
\hline Cancer & 73 & 19.7 & 15.2 & $.309 \#$ \\
\hline Diabetes mellitus & 86 & 21.1 & 18.4 & $.630 \#$ \\
\hline Neurological disease & 59 & 23.7 & 10.8 & $.004 \#$ \\
\hline Chronic intestinal disease & 38 & 9.2 & 8.1 & $.820 \#$ \\
\hline Other chronic disease & 121 & 19.7 & 27.8 & $157 \#$ \\
\hline \multicolumn{2}{|c|}{$\begin{array}{l}\text { Co-morbidity (> } 1 \text { disease), mean } \mathrm{nr} \text { of diseases } \\
\text { (SD) }\end{array}$} & $2.0(1.0)$ & $1.8(1.0)$ & \\
\hline No & 231 & 43.4 & 52.0 & $209 \#$ \\
\hline Yes & 226 & 56.6 & 48.0 & \\
\hline IIIness duration, M (SD) & & $10.2(10.7)$ & $10.5(9.8)$ & \\
\hline $1-5$ years & 154 & 39.5 & 33.1 & $.525 \# \#$ \\
\hline $6-15$ years & 206 & 43.4 & 46.1 & \\
\hline$>15$ years & 91 & 17.1 & 20.8 & \\
\hline Functional disabilities, M (SD) & & $.6(.7)$ & $.5(.7)$ & \\
\hline No or mild (1) & 269 & 50.0 & 63.4 & $.097 \# \#$ \\
\hline Moderate (2) & 126 & 36.5 & 27.0 & \\
\hline Severe (3) & 45 & 13.5 & 9.6 & \\
\hline
\end{tabular}


Alders, I., Henselmans, I., Smits, C., Visscher, T., Heijmans, M., Rademakers, J., Brand, P.L.P., Dulmen, S. van. Patient coaching in specialist consultations. Which patients are interested in a coach and what communication barriers do they perceive? Patient Education and Counseling: 2019, 8, p. 1520-1527

\begin{tabular}{|l|l|l|l|l|}
\hline & & $\begin{array}{l}\text { Interested in a } \\
\text { coach }\end{array}$ & $\begin{array}{l}\text { Not interested in a } \\
\text { coach }\end{array}$ & $\begin{array}{l}\text { p- } \\
\text { value }\end{array}$ \\
\cline { 2 - 5 } & $\mathrm{n}$ & $(\mathrm{n}=76), \%$ & $(\mathrm{n}=381), \%$ & \\
\hline $\begin{array}{l}\text { Number of health contacts last year, } \mathrm{M} \\
\text { (SD) }\end{array}$ & & $1.9(1.5)$ & $1.9(1.4)$ & \\
\hline $0-5$ & 134 & 22.4 & 30.7 & .222\#\# \\
\hline $6-10$ & 143 & 30.3 & 31.5 & \\
\hline$>10$ & 180 & 47.4 & 37.8 & \\
\hline Information preference, M (SD) & & $2.2(.6)$ & $2.3(.6)$ & $.066 \# \#$ \\
\hline 0-6, limited: the least possible (1) & 44 & 8.0 & 10.1 & \\
\hline $7-9$, extended: medium (2) & 227 & 62.7 & 48.0 & \\
\hline 10, complete: as much as possible (3) & 179 & 29.3 & 41.9 & \\
\hline Health literacy, M (SD) & & $9.1(2.4)$ & $10.2(2.2)$ & \\
\hline 0-9 (low) & 126 & 48.0 & 23.9 & \\
\hline$>9$ (high) & 326 & 52.0 & 76.1 & \\
\hline Activation level (PAM), M (SD) & & $2.5(1.1)$ & $2.8(1.1)$ & \\
\hline Level 1 (weak) & 84 & 27.4 & 18.1 & \\
\hline Level 2 & 74 & 23.3 & 16.1 & \\
\hline Level 3 & 132 & 26.0 & 31.9 & \\
\hline Level 4 (strong) & 137 & 23.3 & 33.9 & \\
\hline
\end{tabular}

Sample size ranges from 427 to 457 , due to occasional missing cases.

$\mathrm{M}=$ mean; SD standard deviation; $\mathrm{PAM}=$ patient activation measure; $\mathrm{COPD}=$ Chronic Obstructive

Pulmonary Disease.

\# Fisher's exact test (2-sided).

\#\# Pearson chi square.

Table 2. Level of perceived efficacy and barriers in patients with and without interest in a coach $(n=457)$.

\begin{tabular}{|l|l|l|l|l|l|}
\hline & & & $\begin{array}{l}\text { Interested in a } \\
\text { coach }\end{array}$ & $\begin{array}{l}\text { Not interested in a } \\
\text { coach }\end{array}$ & $\begin{array}{l}\text { p- } \\
\text { value }\end{array}$ \\
\hline & $\mathrm{n}$ & $(\mathrm{n}=76), \%$ & $(\mathrm{n}=381), \%$ & \\
\hline Perceived Efficacy (PEPPI), M (SD) & & $3.6(.9)$ & $4.0(.7)$ & \\
\hline $1-3$ (not confident) & 92 & 38.2 & 16.6 & $<.001$ \\
\hline$>3$ (confident) & 363 & 61.8 & 83.4 & \\
\hline Barriers, mean nr of mentioned barriers (SD) & & $4.3(4.1)$ & $1.7(2.8)$ & $<.001$ \\
\hline 1 & Feeling tense & 90 & 50.0 & 14.2 & $<.001$ \\
\hline 2 & Burdensome to talk about the subject & 36 & 19.4 & 5.8 & $<.001$ \\
\hline 3 & Looking up to the provider & 28 & 16.9 & 4.3 & .042 \\
\hline 4 & Feeling embarrassed about the subject & 13 & 6.9 & 2.1 & $<.001$ \\
\hline 5 & Uncertainty about own understanding & 54 & 33.8 & 8.0 & .001 \\
\hline 6 & $\begin{array}{l}\text { Expecting an annoyed/offended response from } \\
\text { provider }\end{array}$ & 34 & 17.3 & 5.5 & .002 \\
\hline 7 & Perception there is too little time & 115 & 40.5 & 22.4 & .005 \\
\hline 8 & Belief subject is not important enough & 74 & 28.0 & 14.0 & $<.001$ \\
\hline 9 & Not knowing how to discuss the subject & 64 & 32.0 & 10.6 & \\
\hline
\end{tabular}


Alders, I., Henselmans, I., Smits, C., Visscher, T., Heijmans, M., Rademakers, J., Brand, P.L.P., Dulmen, S. van. Patient coaching in specialist consultations. Which patients are interested in a coach and what communication barriers do they perceive? Patient Education and Counseling: 2019, 8, p. 1520-1527

\begin{tabular}{|l|l|l|l|l|l|}
\hline & & & $\begin{array}{l}\text { Interested in a } \\
\text { coach }\end{array}$ & $\begin{array}{l}\text { Not interested in a } \\
\text { coach }\end{array}$ & $\begin{array}{l}\text { p- } \\
\text { value }\end{array}$ \\
\hline & & $\mathrm{n}$ & $(\mathrm{n}=76), \%$ & $(\mathrm{n}=381), \%$ & \\
\hline 10 & Remembering the subject only afterwards & 131 & 46.7 & 25.4 & $<.001$ \\
\hline 11 & $\begin{array}{l}\text { Not finding the right moment to bring } \\
\text { Something up }\end{array}$ & 63 & 35.1 & 9.8 & $<.001$ \\
\hline 12 & Not wanting to be bothersome & 89 & 37.8 & 16.1 & $<.001$ \\
\hline 13 & Not knowing what to ask & 48 & 25.7 & 7.7 & $<.001$ \\
\hline 14 & Fearing the answer to my question & 18 & 6.9 & 3.4 & .185 \\
\hline 15 & $\begin{array}{l}\text { Belief provider cannot provide solution/answer } \\
\text { anyway }\end{array}$ & 46 & 17.8 & 8.8 & .033 \\
\hline 16 & Belief subject is not part of this providers task & 37 & 21.6 & 5.6 & $<.001$ \\
\hline 17 & Not knowing what is expected from me & 45 & 23.7 & 7.1 & $<.001$ \\
\hline
\end{tabular}

Sample size ranges from 427 to 457 , due to occasional missing cases. PEPPI = perceived efficacy in patient provider interaction. $\mathrm{M}=$ Mean; $\mathrm{SD}=$ Standard Deviation.

Table 3. Multivariate associations between patient interest in a coach and age, neurological disease, health literacy, perceived efficacy and barriers $(n=457)$.

\begin{tabular}{|c|c|c|c|c|c|c|c|c|}
\hline & \multicolumn{3}{|c|}{ model 1} & \multicolumn{3}{|c|}{ model 2} & \multicolumn{2}{|c|}{ model 3} \\
\hline & $\begin{array}{l}\mathrm{p}- \\
\text { value }\end{array}$ & $\mathrm{aOR}$ & $(95 \% \mathrm{Cl})$ & $\begin{array}{l}p- \\
\text { value }\end{array}$ & $\mathrm{aOR}$ & $(95 \% \mathrm{Cl})$ & $\begin{array}{l}\mathrm{p}- \\
\text { value }\end{array}$ & aOR $(95 \% \mathrm{Cl})$ \\
\hline Age (<65 vs $\geq 65$ yrs) & .048 & 0.58 & $\begin{array}{l}0.34- \\
0.99)\end{array}$ & .106 & .63 & $\begin{array}{l}(0.37- \\
1.10)\end{array}$ & .146 & $0.62\left(\begin{array}{l}(0.32- \\
1.18)\end{array}\right.$ \\
\hline Neurological disease (yes or no) & .002 & 0.36 & $\left(\begin{array}{l}0.19- \\
0.70)\end{array}\right.$ & .006 & .38 & $\begin{array}{l}(0.19- \\
0.76)\end{array}$ & .004 & $0.32\left(\begin{array}{l}(0.14- \\
0.70)\end{array}\right.$ \\
\hline $\begin{array}{l}\text { Health literacy level }(0-9=\text { low vs }>9= \\
\text { high) }\end{array}$ & & & & .002 & 2.40 & $\left(\begin{array}{l}(1.37- \\
4.21)\end{array}\right.$ & .290 & $1.44\left(\begin{array}{l}(0.73- \\
2.85)\end{array}\right.$ \\
\hline $\begin{array}{l}\text { Perceived efficacy in patient provider } \\
\text { interaction }(1-3=\text { low vs }>3=\text { high })\end{array}$ & & & & .002 & 2.58 & $8 \begin{array}{l}(1.43- \\
4.66)\end{array}$ & 156 & $1.74\left(\begin{array}{l}(0.81- \\
3.73)\end{array}\right.$ \\
\hline \multicolumn{9}{|l|}{ Barriers (yes or no) } \\
\hline 1. Feeling tense & & & & & & & .022 & $2.76\left(\begin{array}{l}(1.16- \\
6.58)\end{array}\right.$ \\
\hline 2. Burdensome to talk about the subject & & & & & & & .811 & $1.14\left(\begin{array}{l}(0.39- \\
3.35)\end{array}\right.$ \\
\hline 3. Looking up to the provider & & & & & & & .663 & $1.32\left(\begin{array}{l}(0.38- \\
4.58)\end{array}\right.$ \\
\hline $\begin{array}{l}\text { 4. Feeling embarrassed about the } \\
\text { subject }\end{array}$ & & & & & & & .304 & \begin{tabular}{|l|l|}
0.37 & $(0.57-$ \\
$2.44)$
\end{tabular} \\
\hline $\begin{array}{l}\text { 5. Uncertainty about own } \\
\text { understanding }\end{array}$ & & & & & & & .007 & $3.59 \begin{array}{l}(1.42- \\
9.13)\end{array}$ \\
\hline \multicolumn{2}{|c|}{$\begin{array}{l}\text { 6. Expecting annoyed/offended response from } \\
\text { provider }\end{array}$} & & & & & & .866 & $1.12\left(\begin{array}{l}(0.30- \\
4.12)\end{array}\right.$ \\
\hline 7. Perception there is too little time & & & & & & & .108 & $0.47\left(\begin{array}{l}(0.19- \\
1.18)\end{array}\right.$ \\
\hline 8. Belief subject is not important & & & & & & & .511 & $0.73(0.29$ \\
\hline
\end{tabular}


Alders, I., Henselmans, I., Smits, C., Visscher, T., Heijmans, M., Rademakers, J., Brand, P.L.P., Dulmen, S. van. Patient coaching in specialist consultations. Which patients are interested in a coach and what communication barriers do they perceive? Patient Education and Counseling: 2019, 8, p. 1520-1527

\begin{tabular}{|c|c|c|c|c|c|c|c|c|}
\hline & \multicolumn{3}{|c|}{ model 1} & \multicolumn{3}{|c|}{ model 2} & \multicolumn{2}{|c|}{ model 3} \\
\hline & $\begin{array}{l}\mathrm{p}- \\
\text { value }\end{array}$ & aOR & $(95 \% \mathrm{Cl})$ & $\begin{array}{l}p- \\
\text { value }\end{array}$ & $\mathrm{aOR}$ & $(95 \% \mathrm{Cl})$ & $\begin{array}{l}p- \\
\text { value }\end{array}$ & $\mathrm{aOR}(95 \% \mathrm{Cl})$ \\
\hline enough & & & & & & & & 1.85) \\
\hline $\begin{array}{l}\text { 9. Not knowing how to discuss the } \\
\text { subject }\end{array}$ & & & & & & & 157 & $0.46 \begin{array}{l}(0.16- \\
1.35)\end{array}$ \\
\hline $\begin{array}{l}\text { 10. Remembering the subject only } \\
\text { afterwards }\end{array}$ & & & & & & & .890 & $0.95\left(\begin{array}{l}(0.44- \\
2.05)\end{array}\right.$ \\
\hline \multicolumn{2}{|l|}{$\begin{array}{l}\text { 11. Not finding the right moment to bring } \\
\text { something up }\end{array}$} & & & & & & .069 & $2.69\left(\begin{array}{l}(0.93- \\
7.80)\end{array}\right.$ \\
\hline 12. Not wanting to be bothersome & & & & & & & .749 & $1.16\left(\begin{array}{l}(0.46- \\
2.95)\end{array}\right.$ \\
\hline 13. Not knowing what to ask & & & & & & & .615 & $0.77\left(\begin{array}{l}0.27- \\
2.16)\end{array}\right.$ \\
\hline 14. Fearing the answer to my question & & & & & & & .505 & $0.52 \begin{array}{l}(0.13- \\
2.78)\end{array}$ \\
\hline \multicolumn{3}{|c|}{$\begin{array}{l}\text { 15. Belief provider cannot provide solution/answer } \\
\text { anyway }\end{array}$} & & & & & .673 & $0.79\left(\begin{array}{l}0.27- \\
2.32)\end{array}\right.$ \\
\hline $\begin{array}{l}\text { 16. Belief subject is not part of } \\
\text { provider's task }\end{array}$ & & & & & & & $<.001$ & $8.73\left(\begin{array}{l}(2.76- \\
27.65)\end{array}\right)$ \\
\hline $\begin{array}{l}\text { 17. Not knowing what is expected from } \\
\text { me }\end{array}$ & & & & & & & .428 & $1.49\left(\begin{array}{l}0.56- \\
3.95)\end{array}\right.$ \\
\hline
\end{tabular}

Sample size ranges from 424 to 457 due to occasional missing values. Multivariate analysis, method enter, dependent variable: interest in a patient coach, constant included in model aOR = adjusted Odds Ratio; $(95 \% \mathrm{Cl})=95 \%$ confidence interval for aOR. 